\title{
Metode Hybrid dalam Perancangan Terminal Kampung Melayu Jatinegara, Jakarta Timur
}

\author{
Muhammad Nuril Ardan dan Angger Sukma Mahendra \\ Departemen Arsitektur, Fakultas Teknik Sipil dan Perencanaan, Institut Teknologi Sepuluh Nopember (ITS) \\ e-mail: angger@arch.its.ac.id
}

\begin{abstract}
Abstrak - Kota dengan segala perkembangannya menarik orang dengan segala etnis, suku dan budayanya untuk hijrah dari desa ke kota. Hal ini menjadikan komposisi kota semakin heterogen dan beragam. Heterogenitas inilah yang kemudian secara tidak langsung menciptakan "batasan" (red. Segregasi) antar kelompok tertentu (dalam hal ini etnis) dalam kawasan perkotaan. dan hal ini pula yang memungkinkan terjadinya konflik perkotaan. Heterogenitas perkotaan perlu di biaskan (red. Agregasi). Agar kota tetap kondusif dengan segala kompleksitasnya. Dengan menggunakan pendekatan ruang dan aktivitas manusia yang beragam karakteristik etnis, diharapakan batasan-batasan tersebut akan terbiaskan. Melalui arsitektur yang berorientasi pada penyelesaian permsalahan sosial, perancangan pasar dan terminal sebagai ruang interaksi di masyarakat menjadi bagian dari respons segregasi. Dengan pendekatan agregasi dan penyelesaian melalui metode hybrid, rancangan arsitektur diupayakan menjadi rancangan yang interaktive dan bermanfaat
\end{abstract}

Kata Kunci-Segregasi, Agregasi, Arsitektur, Hybrid.

\section{PENDAHULUAN}

$\mathrm{K}$ OTA dengan segala perkembangannya menarik orang dengan segala etnis, suku dan budayanya untuk hijrah dari desa ke kota. Hal ini menjadikan komposisi kota semakin heterogen dan beragam. Heterogenitas inilah yang kemudian secara tidak langsung menciptakan "batasan" (red. Segregasi) antar kelompok tertentu (dalam hal ini etnis) dalam kawasan perkotaan. dan hal ini pula yang memungkinkan terjadinya konflik perkotaan. Heterogenitas perkotaan perlu di biaskan (red. Agregasi). Agar kota tetap kondusif dengan segala kompleksitasnya. Jakarta sebagai kota metropolitan terbesar di Indonesia tentu menyimpan semua kerumitan perkotaan serta sosial sebagimana yang terbahas diatas. (Gambar 1.)

Terminal kampung melayu berada di daerah jatinegara, jakarta timur. Kawasan ini merupakan kawasan padat aktivitas dan merupakan jalur sirkulasi yang penuh, baik itu pedestrian atau pejalan kaki maupun kendaraan. (Gambar 2). Eksistingnya yang berupa terminal sangat jelas mengindikasikan bahwa kawasan ini merupakan kawasan yang ramai dan merupakan ruang publik di lingkungannya. Tempat ini juga merupakan tempat transit moda kendaraan dan manusia yang akan dan dari Jakarta Pusat ke Jakarta Timur ataupun keluar Jakarta ke arah Depok. (Gambar 3). Berdasarkan Peraturan Daerah Provinsi Daerah Khusus Ibukota Jakarta Nomor 1 Tahun 2014 Tentang Rencana Detail Tata Ruang Dan Peraturan Zonasi Kawasan ini memiliki kode lokasi 006.C.I.a.b dan 007.S.6.a.b dimana area ini diarahkan untuk dimanfaat kan sebagai ruang layanan pelayanan sosial (terminal) serta area campuran. (Gambar 4).

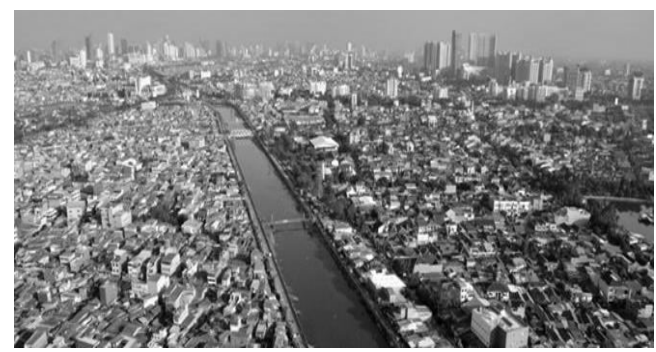

Gambar 1. Kepadatan dan komplesitas Jakarta.

(Sumber: viva.co.id "mengintip kepadatan jakarta dari angkasa”)

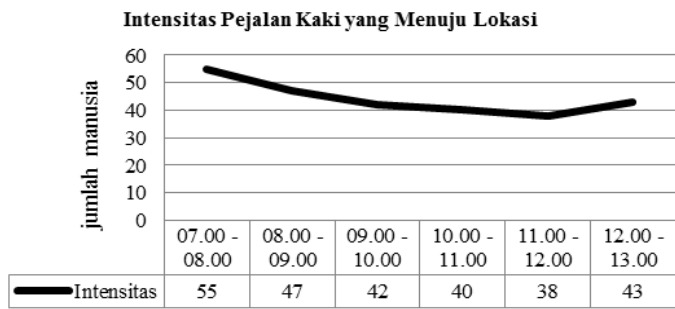

Gambar 2. Tabel intensitas pejalan kaki.

(Sumber: Dokumentasi Pribadi)

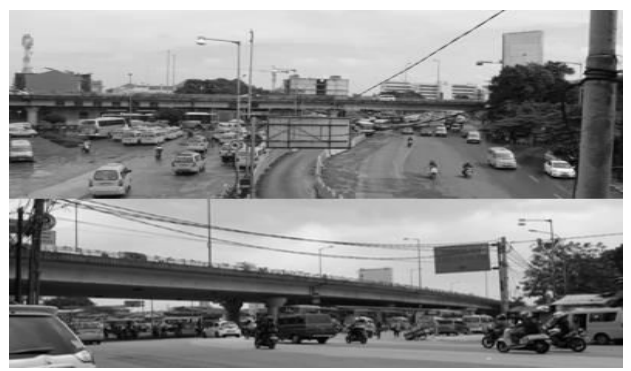

Gambar 3. Suasana Terminal Kampung Melayu.

(Sumber: Dokumentasi Pribadi)

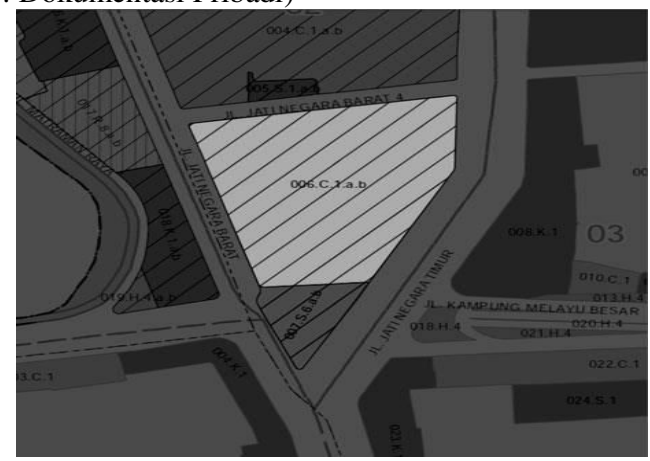

Gambar 4. Zonasi lahan/site.

(Sumber: dcktrp pemprov. dki Jakarta) 
Perancangan terminal kampung melayu inidiharapkan dapat meningkatkan kualitas interaksi antar kelompok segregasi. Interaksi akan mampu menambah kualitas untuk salaing berkomunikasi dan berinteraksi antar kelompok masyarakat. Dengan menggunakan pendekatan ruang dan aktivitas manusia yang beragam karakteristik etnis, diharapakan batasan-batasan tersebut akan terbiaskan.

\section{METODA PERANCANGAN}

Hybrid Architecture merupakan penggabungan beberapa aspek berbeda tentunya dalam ruang lingkup arsitektural. Hybrid merupakan hasil persilangan atau penggabungan dari sesuatu yang berbeda. Penekanan pengertian hybrid ini adalah "hasil" dari persilangan atau penggabungan. (Febriana D.S. Rompis dan Sangkertadi: 2011)

Menurut Jencks, hybrid merupakan suatu metode untuk menciptakan sesuatu dengan pola-pola lama (sejarah), namun dengan bahan dan teknik yang baru. (Jencks, C. :1997)

Dengan kata lain menggabungkan bentuk-bentuk tradisional dengan teknik modern. Metode hybrid dinyatakan melalui tahapan-tahapan quatation, manipulasi elemen, dan unifikasi dan penggabungan. Metode ini memiliki kesamaan dengan versi Ventury, yang meliputi tatanan, fragmentasi , infeksi dan juxtaposition atau superimposisi.

(Ikhwanuddin: 2005)

Adapun tahapan dari metode Hybrid ini adalah sebagai berikut (Gambar 5).:

1. Elektik atau Quotation

Artinya menelusuri dan memilih pembendaharaan bentuk dan elemen arsitektur dari masa lalu yang dianggap potensial untuk diangkat kembali. Asumsi dasarnya adalah telah mapannya kode dan makna yang diterima dan dipahami oleh masyarakat

2. Manipulasi dan Reduksi

Elemen-elemen elektik atau hasil dari quotation tersebut selanjutnya dimanipulasi ataudimodifikasi dengan caracara yang dapat menggeser, mengubah, dan atau memutarbalikanmakna yang telah ada.

Beberapa teknik manipulasi ini meliputi:

- Reduksi dan siplikasi - Disorientasi

- Repetisi - Disproporsi

- Distorsi bentuk - Dislokasi

3. Penggabungan

Penggabungan dan penyatuan beberapa elemen yang telah dimanipulasi atau dimodifikasi ke dalam desain yang telah ditetapkan order-nya.

\section{HASIL DAN EKSPLORASI}

\section{A. Tahap Elektik / Quotation}

1. Pemilihan fungsi dari obyek pasar tradisional dengan terminal untuk kemudian digabungkan. Fungsi yang dipilih adalah koridor dan lobi dalam pasar dengan koridor pada terminal

Pemilihan bentukan masa lalu/tradisional berupa arsitektur rumah adat Betawi, dimana unsur oranamentasi dalam Arsitektur betawi menjadi unsur utama ciri dari rancangan yang akan dihadirkan.

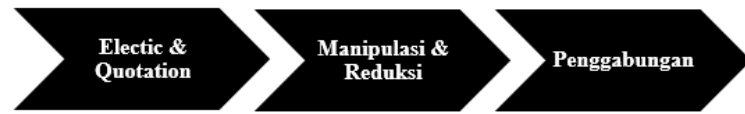

Gambar 5. Tahapan Metode Hybrid Arsitektur

(Sumber: Dokumentasi Pribadi)
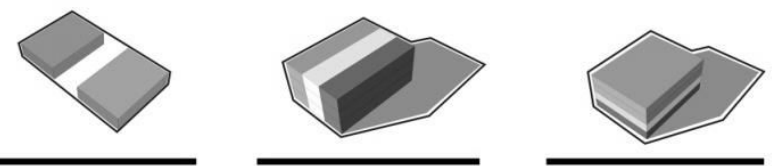

Gambar 6. Tahapan Manipulasi dalam Metode Hybrid Arsitektur. (Sumber: Dokumentasi Pribadi)
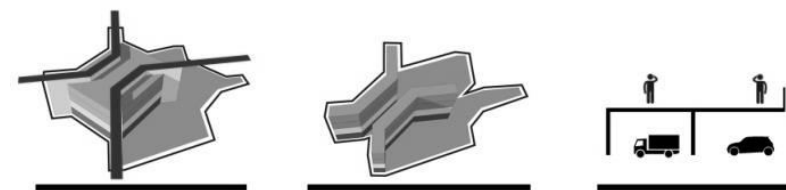

Gambar 7. Tahapan Penggabungan dalam Metode Hybrid Arsitektur (Sumber: Dokumentasi Pribadi)

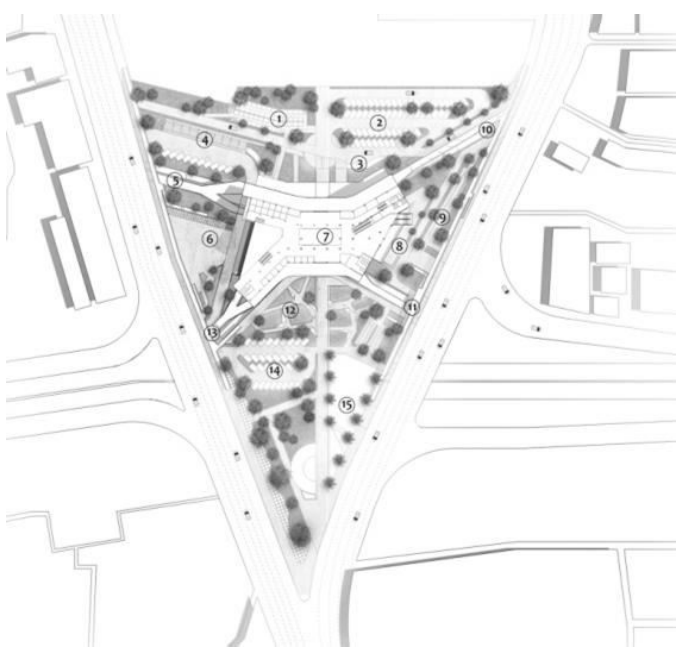

Gambar 8. Site Plan Obyek rancang.

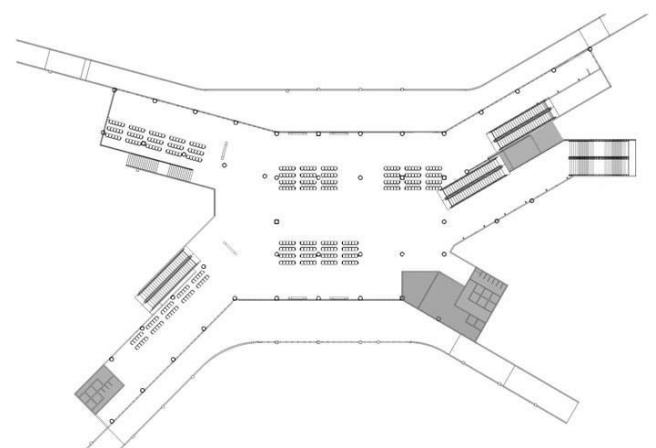

Gambar 9. Denah Lantai Basemen.

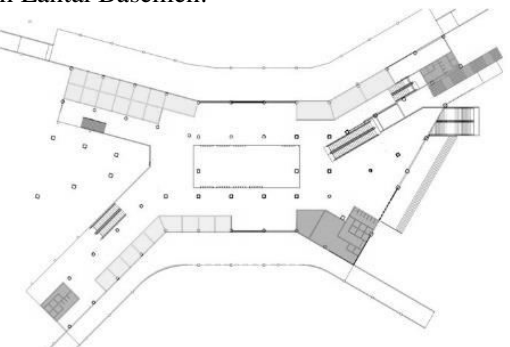

Gambar 10. Denah Lantai 1. 


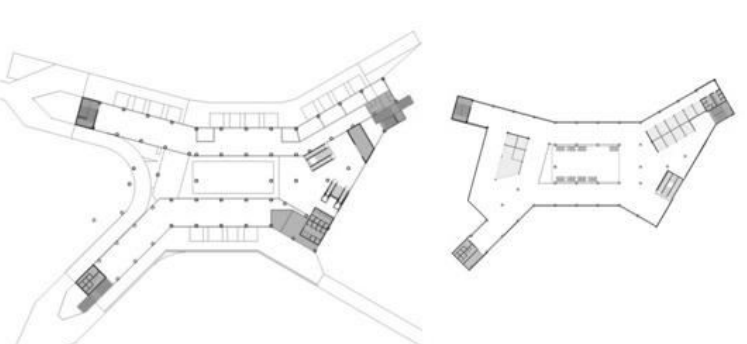

Gambar 11. Denah Lantai 2 dan 3.
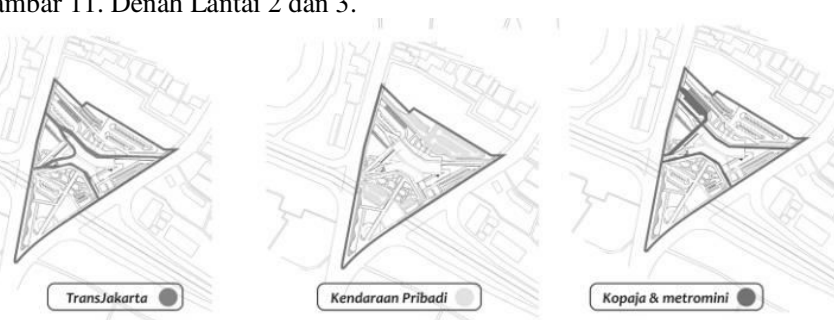

Gambar 12. Sirkulasi Antar Moda.

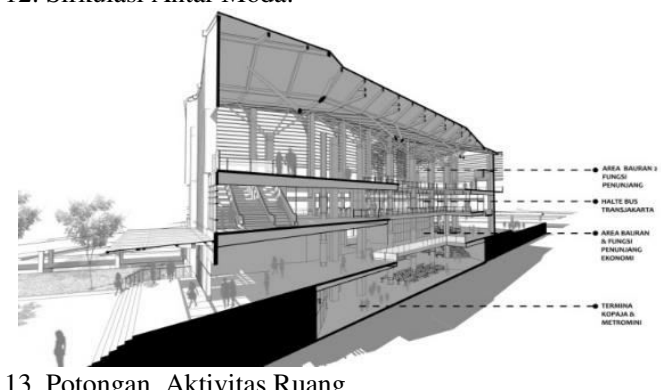

Gambar 13. Potongan Aktivitas Ruang.

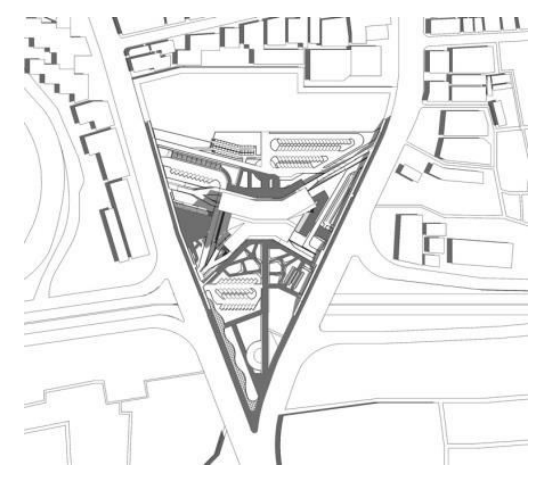

Gambar 14. Pola Sirkulasi Manusia.
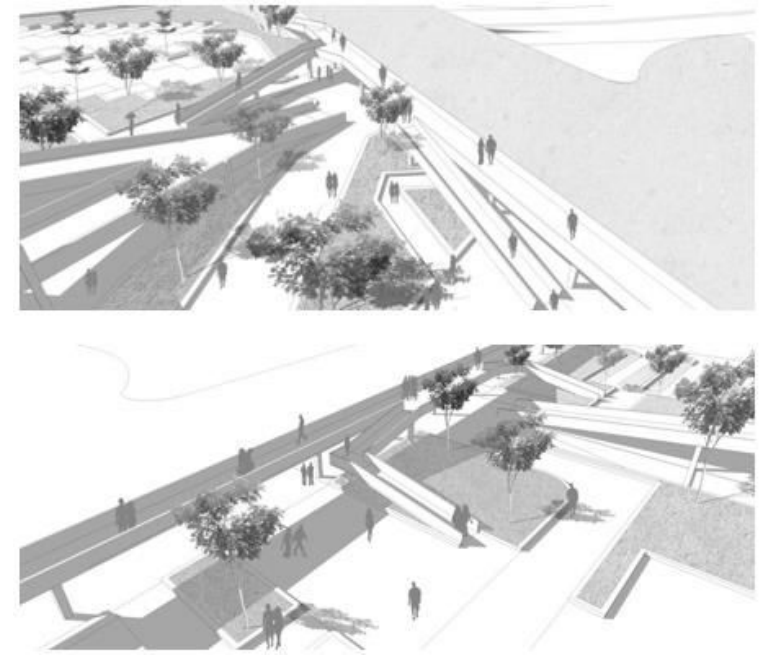

Gambar 15. High Pedestrianway.

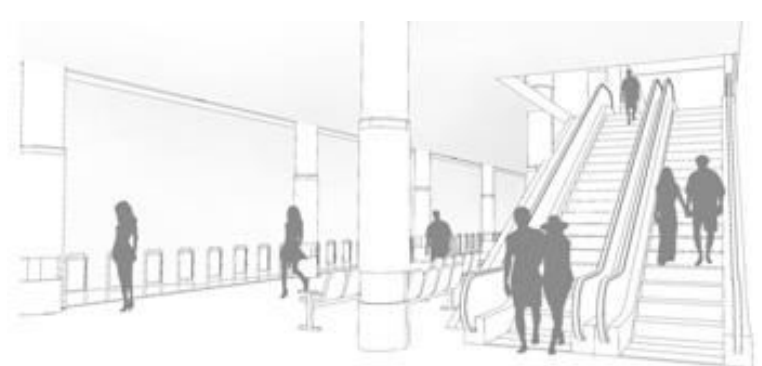

Gambar 16. Lift \& Eskalator Ruang.

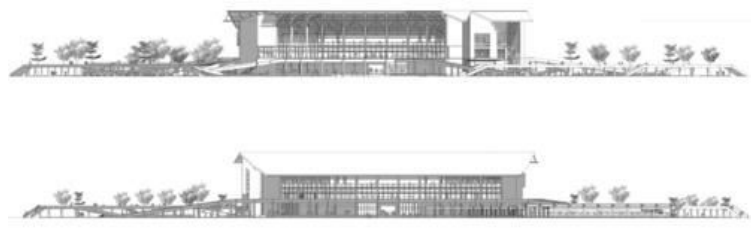

Gambar 17. Tampak Bangunan.

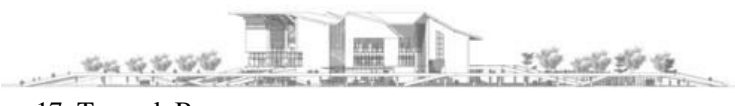

\section{B. Tahap Manipulasi / Modifikasi}

1. Bauran ruang berupa koridor dibuat sebagai identitas kuat dari aspek interaksi (Gambar 6).

2. Modifikasi ornamen menjadi bagian dari elemen struktur

\section{Tahap Penggabungan}

1. Hasil penggabungan antara terminal dan pasar dalam satu sistem dan bangunan membentuk suatu tatanan masa baru, dimana akhirnya terbentuk masa transisi diantara kedua fungsi utama ini. (Gambar 7).

2. Area transisi ini lah yang kemudian dimaksimalkan sebagai ruang interaksi dan agregasi dalam rancangan

3. (Gambar 8).

4. Selain itu, peggabungan model tradisional dan modern ini membentuk arsitektur perpaduan baru sebagiamana konsep hybrid ini diterapkan

1) Sirkulasi Kendaraan

Pola sirkulasi kendaraan berangkat dari model sirkulasi eksisting. Dimana terdapat 3 lengkung utama jalur moda transportasi (Gambar 12).. Yakni:

1. 3 rute bus TransJakarta dari arah Utara dan puter balik di lahan

2. 1 rute dari arah Selatan yang puterbalik

3. 1 rute lurus, masuk dari pintu Selatan dan keluar dari pintu utara

Sirkulasi moda dibuat menjadi 2 trap/level utama. Dimana level 1 (basement) sebagai area Kopaja dan Metro mini, dan level 2 (Lantai 2) sebagai area Halte TransJakarta. (Gambar 13).

2) Sirkulasi Manusia

Bangunan dirancang untuk dapat terakses dari segala arah, utamanya pada sisi barat dan timur lahan, yang mana menjadi akses utama memasuki bangunan. pola sirkulasi disusun berdasar pola pergerakan (eksisting) dalam kawasan. (Gambar 14). Pergerakan sirkulasi dalam bangunan dibantu oleh adanya tangga, eskalator dan lift. High Pedestrianway untuk 
mengatasi cross sirkulasi antara pergerakan manusia dan sirkulasi kendaraan (Gambar 15-16).

\section{KESIMPULAN}

Metode merupakan sebuah sintesa dari analisis dan penyusunan sintesis yang dapat menjadi penerangan, wawasan dari pemecahan masalah.

Metode hybrid bisa diterapkan dalam skema perancangan dengan konsep penggabungan dua atau lebih fungsi, style, pendekatan Arsitektur. Sehingga dalam hal ni akan dapat memunculkan sebuah Arsitetur yang kombinatif, kontekstual dan dapat interaktif terhadap isu permaslahan yang ada.

Sebagaimana dalam perancangan Terminal kampung melayu ini, metode hybrid cukup tepat untuk dipilih dimana inti dari metode hybrid berupa penyatuan dan solusi dari permasalahn dalam konteks Agregasi/Segregasi juga penyatuan. Namun dalam penerapannya terhadap desain, perlu diulas dan diperdalam kembali khusunya terhadap fungsi, style dan material yang akan dihybridkan satu sama lain. Sehingga aspek utama dari metode ini akan dapat dirasakan dan terlihat.

\section{DAFTAR PUSTAKA}

[1] Huda. (2015). 68\% penduduk indonesia diramalkan sesaki kota pada 2025.[Online].Website:http://www.cnnindonesia.com/ekonomi/2015012 6124532-78-27377/68-persen penduduk-indonesia-diramalkan-sesakikota-pada-2025/

[2] Peraturan Daerah Provinsi Daerah Khusus Ibukota Jakarta Nomor 1 Tahun 2014 Tentang Rencana Detail Tata Ruang Dan Peraturan Zonasi

[3] Melati, Putri. (2014). Memahami teori interaksi sosial. [Online]. Website:http://ensiklo.com/2015/08/memahami-teori-interaksi-sosial/

[4] (Jurnal Arsitektur UNSRAT) D.S. Rompis, Febriana dan Sangkertadi."Hibridisasi Fungsi Pasar Tradisonal dan Mall, Suatu Studi Imajinatif".Journal.

[5] Surasetja, Irwan. 2007. Bahan Ajar Pengantar Arsitektur : "Fungsi, Ruang, Bentuk Dan Ekspresi Dalam Aristektur". Jakarta: Arena press

[6] Jencks, C. 1997. Theory And Manifestoes. Academy Edition. New York.

[7] Ikhwanuddin. 2005. Menggali Pemikiran Postmoderisme Dalam Arsitektur. Gajah Mada University Press. Jogyakarta.

[8] Pena, William. 2001. Fourth edition: problem seeking an architectureal programming primer. New York: HOK Group, Inc.

[9] Neufert, Ernest. 1996. Data Arsitek 1. Jakarta: Erlangga 